\title{
Applications of a "Carry-Over" Enhanced DSBM Intertemporal Technical Efficiency Model on the Taiwanese 5G Industry
}

\author{
Day-Yang Liu', Hui-Chien Fan², Joseph C.P. Shieh ${ }^{3}$ and Cheng-Hsien Lin ${ }^{4}$
}

\begin{abstract}
Taiwan has proven itself successful at both inventing the key technologies leading to the development of $5 \mathrm{G}$ (fifth generation wireless technology)-related industries and serving as an indispensable link in the burgeoning 5G-industrial global supply chain. This study analyzes the current state of Taiwan's 5G industry via the utilization the purpose of this study is to the Dynamic Slacks-Based Measure (DSBM). To achieve this purpose, a dynamic-data production process model was developed to analyze the $5 \mathrm{G}$ industry's overall relative efficiency. Results indicate that (1) key chip-producing companies typically experience increased efficiency following $5 \mathrm{G} R \& \mathrm{D}$ industry development investment, and that said companies' relative efficiency is, indeed, affected positively by R\&D investment; and (2) key chip companies' relative increases of efficiency were higher than those of brand terminal and downstream-industry-category companies, while companies with higher levels of $R \& D$ investment exhibited relatively higher and more significant levels of efficiency. Finally, it was discovered that the relative efficiency of Taiwan's 5G-related industries' R\&D investment was, indeed, statistically significant in terms of the Taiwanese government's industrial policies regarding $5 \mathrm{G}$ R\&D investment.
\end{abstract}

Keywords: Dynamic Slacks-Based Measure (DSBM), 5G Industry, R\&D Inputs.

${ }^{1}$ Graduate Institute of Finance National Taiwan University of Science and Technology.

2 School of Management National Taiwan University of Science and Technology.

${ }^{3}$ Graduate Institute of Finance National Taiwan University of Science and Technology.

${ }^{4}$ Department of Financial Management National Defense University.

Article Info: Received: December 3, 2021. Revised: December 27, 2021.

Published online: December 30, 2021. 


\section{Introduction}

Recent advances in the development of new-generation mobile communication networks such as $3 \mathrm{G}, 4 \mathrm{G}$, and $5 \mathrm{G}$ (hereafter referred to as "new-generation networks") have been critical factors in the creation of the mobile Internet (Jia, 2016). This new generation of networks - particularly 5G -has forced all players in the communications industry to not only pay close attention to the value but also the performance of their network investments. The effective implementation of new mobile digital services (hereafter referred to as "new services") is critical to a company's success (Harb, 2017). While the various test methods used to gauge the communications industry's performance are becoming increasingly mature, exploratory factor analysis and principal factor analysis are still currently used to measure and evaluate its performance. While Structural Equation Modelling (SEM), for example, remains a commonly-employed such performance measurement method for the communications industry, its lack of sufficient theoretical support for explaining the relationships between the models' facets has been pointed out as its principal shortcoming (Gerpott \& Ahmadi, 2015).

The authors opted to employ SEM research methods to analyze the statistical data derived in this study to measure the relative efficiency of the overall communications industry because the Data Envelopment Analysis (DEA) model is considered superior to other performance measurement methods (Kumar, Shankar \& Debnath, 2015). In doing so, a set of input-output indicators were inserted into a complete DEA model system to measure and compare more effectively the factors leading to relative efficiency. Empirical research was used to analyze dynamically the difference in the relative efficiency of Taiwan's 5G industry prior to and following network upgrade periods, as well as to provide guidance for and offer suggestions to companies planning to invest in $5 \mathrm{G}$ development and subsequent new-generation networks.

The highly-anticipated emergence of the $5 \mathrm{G}$ mobile network has been the focus of much research and development since 2019, with nearly 100 countries investing in their 5G communication infrastructures in 2020. According to the IHS' (Information Handling Services) 5G Economy Research Report, 5G will generate more than US\$3 trillion worldwide, create more than 22 million employment opportunities, and continue to be used in AR/VR (Augmented Reality and Virtual Reality), industrial automation and other related applications. The vigorous development of 5G-related services is estimated to drive global economic activity to an output value of more than US\$12.3 trillion in the years to come.

As 5G applications become increasingly common and influential, 5G will also be introduced into many so-called vertical fields. According to statistics from Ericsson, the Swedish telecommunications equipment manufacturer, the top-ten most important professional vertical fields have gradually begun to integrate applications from 2019 to 2026. It is expected that $5 \mathrm{G}$ digitization this year will yield an output value of US\$1.32 trillion to the telecommunications industry.

To put this into perspective, in 2019, the output value of the telecommunications 
industry fostered by the introduction of $5 \mathrm{G}$ in the 10 major vertical industries was only US $\$ 5$ billion, but is predicted to grow to US $\$ 879$ billion by 2024 . The compound annual growth rate (CAGR) from 2019 to 2024 is estimated to rise as high as $181 \%$ and from 2024 to 2026 might even soar to over $23 \%$. The MIC estimates $5 \mathrm{G}$ will drive the output value of the information and communications industries up to US\$1.32 trillion and, among these, the energy sector is expected to yield the highest output value of US\$248 billion - accounting for $19 \%$ of said growth - due to the fact that it has already increased by $14 \%$ since the introduction of $5 \mathrm{G}$ technology. Regarding the output value of other key fields, the output value of the manufacturing industry increased by US $\$ 238$ billion and accounted for $18 \%$, with the overall revenue growth rate of about $11 \%$. In the public security business, this was US\$172 billion, accounting for $13 \%$, with an overall growth rate reaching $16 \%$; that of the medical care industry was US\$1,580 billion, accounting for $12 \%$, with an overall growth rate of about $11 \%$, which together constitute the four major industries brought about by $5 \mathrm{G}$ R\&D investment.

Moreover, the output value of other industries such as the mass transportation industry increased by US $\$ 132$ billion, accounting for $10 \%$, with the overall growth rate reaching $17 \%$; the media and entertainment industry was US\$119 billion, accounting for $9 \%$, and the growth rate reached 15\%; the automobile industry was US $\$ 106$ billion, accounting for $8 \%$, and the growth rate was as high as $20 \%$; the financial industry was US\$79 billion, accounting for $6 \%$, the growth rate was $10 \%$; the retail industry was US\$53 billion, accounting for $6 \%$, with a growth rate as high as $21 \%$; indeed, even the smallest proportional sector, agriculture, still exhibited a growth rate of $16 \%$ with US\$15 billion.

\section{5G Industry Background and Development}

The first generation of mobile communications technology specifications $(1 \mathrm{G}$, analog voice services) of the mobile wireless communications industry was formulated in the 1980s. Providing clients with mobile voice services, $1 \mathrm{G}$ changed the way people communicated by voice and allowed users access to a fixed-point communication method. This ushered in many conveniences and caused the mobile wireless communication industry to flourish. Since then, mobile wireless communication technology and its accompanying specifications have developed in ten-year cycles, bringing incessant and dramatic changes to the industry.

The following is a brief description of the development stages leading to $5 \mathrm{G}$ development:

1. 1980s: The first generation of mobile technology $1 \mathrm{G}$ first generation (Advanced Mobile Phone System, AMPS) is introduced with the definition of analog voice communication technology as the main technological change.

2. 1990's: The second-generation mobile technology 2G second-generation (Global System for Mobile Communications, GSM) emerges with the definition of digital voice communication as its main technological change.

3. 2000's: 3G third generation (Wideband Code Division Multiple Access, 
WCDMA), the third generation of mobile technology with the development of wireless data capabilities spearheading its main technological change.

4. 2010's: The fourth generation of mobile technology 4G fourth generation (Long-Term Evolution, LTE), focusing on broadband data as its principle technological change.

5. 2020's, the fifth generation of wireless mobile technology, 5G fifth generation (New Radio, NR), specifications were finalized that focused on higher traffic (enhanced Mobile Broadband, eMBB), lower latency, and higher reliability (Ultra Reliable Low) than 4G. Latency Communications (URLCC) and Massive Machine Type Communications (mMTC) also underwent dramatic technological changes.

In March of 2017, the 3GPP (3rd Generation Partnership Project), an umbrella term applied to standards organizations that develop protocols for mobile telecommunications, approved a new $5 \mathrm{G}$ radio technology (NR) standardization time schedule acceleration and launched an early variant of 5G "non-standalone 5G NR," which provided important transition support to both lay the foundation for the early deployment of 5G and meet the needs of enhanced wireless broadband services. 5G NR standardization was completed in 2019 on a large-scale trial deployment basis, and it is expected that the number of $5 \mathrm{G}$ users will exceed 500 million users by the end of 2022 .

The 5G specification goals defined by the $3 \mathrm{GPP}$ aim to achieve the following three performance indicators:

1. Create download speed exceeding the theoretical value of $10 \mathrm{~Gb} / \mathrm{s}$ to meet the needs of wireless broadband and enhanced mobile broadband (eMBB),

2. Support one million massive machine-type communications (MMTC) connections per square kilometer,

3. Minimize the communication delay capability to less than one millisecond (millisecond) to enable ultra-reliable low-latency communications (URLLC).

Wireless communication employs electromagnetic waves to transmit various types of information with the waves' varying frequency types determining their differing communication characteristics and application scenarios. In consideration of the availability of the required wireless spectrum frequency and commercial considerations, $5 \mathrm{G}$ specifications can be set to different frequency bands to satisfy the needs of an entire country, as well as individual markets and an even-wider number of usage scenarios. The frequency range of the $5 \mathrm{G}$ band can be divided into three blocks: 5G-low, 5G-intermediate, and 5G-high frequency.

With the development of multiple frequency band definitions, coupled with increased technological advancements and enhanced eMBB, MMTC, and URLLC, telecom operators in the Netcom industry hope to provide future consumers with more convenient network services and extensively diversified businesses services. The 5G wave has had a tremendous impact on business and created numerous opportunities for different industries. More than half of the Fortune 500 companies in the United States since 2000 have disappeared, underwent mergers or simply gone bankrupt due to their inability to adapt to this ever-changing environment. 
Companies the world over must now rethink their transformations, find new positions in the industry, forge new business models, adjust to new technological trends, seek fresh business opportunities and ascertain new developmental directions to avoid being submerged by this ominous wave. However, the development of $5 \mathrm{G}$ technology has not only presented numerous challenges for the network industry, but also delivered many new business opportunities, as well.

Debnath and Shankar employed the DEA model to obtain the relative efficiency ranking of Indian telecom operators and calculate their relative efficiency (Debnath \& Shankar, 2008). The relative efficiency of Taiwanese telecom operators from 2001 to 2005 was similarly measured by Yang and Chang via a constant and variable regression research method based on scale measurement (Yang \& Chang, 2009). Kumar, Shankar and Debnath investigated key factors affecting Indian consumers' telecommunications services purchase behaviors by developing a framework based on fuzzy analytical hierarchy processes, DEA models and other performance measures. The results of the aforementioned studies demonstrate that the DEA model has a number of comparatively significant advantages, particularly from the perspective of efficiency, when compared with other methods.

\section{Research Design}

\subsection{Research Sample}

In light of the fiercely-competitive 5G market, Taiwanese companies must rely on their current market advantages in semiconductor, computer and precision manufacturing to seize future business opportunities and survive in the current $5 \mathrm{G}$ era. Among these companies, this study uses Cathay Pacific Taiwan 5G+ ETF (exchange-traded funds) as its research objective.

The first ETF in Taiwan stocks to invest $100 \%$ in 5G-technology stocks, Cathay Pacific Taiwan 5G+ETF tracks Taiwan's 5G+ communications index and was chosen as this study's research objective because it is screened by the FactSet industry classification, is a professional financial data company listed on the New York Stock Exchange and Nasdaq, comprises of 45 5G-related sub-industries, and has a complete grasp of the future of 5G. Having even begun to invest in $6 \mathrm{G}$ and 7G investment opportunities, Cathay Pacific Taiwan's index constituent stocks are selected through a three-tiered selection process: the first level is high-purity $5 \mathrm{G}$ stocks - only select Taiwanese-listed stocks that account for more than $50 \%$ of the 5G-industry revenue; the second level is good liquidity stocks, with an average daily turnover of more than 50 million over the past three months; the third tier is profitable and high-performance stocks - stocks of companies with an accumulated EPS greater than 0 over the past four seasons. Following the aforementioned tiered screening, these stocks are finally designated as Top 30 5G Blue-Chip Stocks and weighted according to market capitalization.

The 30 listed (counter) companies in the above-mentioned " $5 \mathrm{G}$ " concept stocks were selected as this study's research samples. Since the goal was to explore the relative efficiency of $5 G R \& D$ investment, the research period was chosen to be 
from the first quarter of 2018 to the fourth quarter of 2020. The financial statements of each company were analyzed, and 360 DMUs (decision-making units) were calculated. The research sample was deemed sufficient to represent the overall $5 \mathrm{G}$ industry, and financial statements were all collected from the "Taiwan Economic News" database. In evaluating the dynamic DEA analysis, each of the companies was regarded as a decision-making unit (DMU) in order to maintain the sample companies' homogeneity. According to Golany and Roll (1989), the homogeneity of samples in DEA must meet the following criteria: The units under consideration must perform the same tasks, have similar goals, and all units must be executed under the same "market conditions."

\subsection{Selection \& Definition of Input and Output Items}

Many scholars have recently employed the concept of multiple inputs and outputs to measure R\&D performance. Supported by the results of many cogent studies, such as Diaz-Balteiro et al. (2006), Eberhart, Maxwell and Siddique (2008), Hashimoto and Haneda (2008), Pandit, Wasley and Zach (2011), this study uses the current year's R\&D expenses as an input variable; operating expenses (including sales expenses and management expenses) as an input variable (Kotabe et al., 2002; Lu et al. 2016, Chen \& Chiang, 2018; Chou , Shao \& Lin, 2012; Lu \& Hung, 2011); the number of employees as an input variable; and market value and operating income as an output variable (Seiford \& Zhu, 1999; Hashimoto \& Haneda, 2008; Lu et al., 2016).

In the first stage of dynamic relative efficiency analysis, liabilities and equities are regarded as input variables, while the "carry-over" value from the previous period is used in the second stage of DEA dynamic analysis. In other words, this study examines the efficiency of the 5G-industry via dynamic DEA, and adds carry-over to the production process between the two stages. The term "carry-over" refers to the application of the companies' balance sheets due to the fact that balance sheets have an inherent time period between periods and, therefore, contain characteristics of the cumulative total. Therefore, this study classifies variables according to the characteristics of assets, liabilities and liabilities as its main research objective. Table 1: describes the present study's selection of variables and operational definitions. 
Table 2: Variables Classification in 5G Companies' Dynamic Production Processes

\begin{tabular}{|c|c|c|c|}
\hline Variables & $\begin{array}{l}\text { Financial } \\
\text { statement }\end{array}$ & $\begin{array}{c}\text { Temporary or } \\
\text { permanent accounts }\end{array}$ & Carry-over \\
\hline \multicolumn{4}{|c|}{ Input } \\
\hline Employees & None & None & $\mathrm{X}$ \\
\hline \multicolumn{4}{|c|}{ Employees: The total number of full-time employees. } \\
\hline R \& D Expenditures & None & None & $\mathrm{X}$ \\
\hline \multicolumn{4}{|c|}{$\begin{array}{l}\text { R \& D Expenditures (Unit: Thousands NTD): the funding spent on creative work } \\
\text { undertaken on a systematic basis to increase the stock of knowledge and utilize this } \\
\text { knowledge to devise new applications. }\end{array}$} \\
\hline Operating Expenses & None & None & $\mathrm{X}$ \\
\hline \multicolumn{4}{|c|}{$\begin{array}{l}\text { Operating Expenses (Unit: Thousands NTD): is an ongoing cost for running a } \\
\text { product, business, or system. }\end{array}$} \\
\hline \multicolumn{4}{|c|}{ Carry-over (Input variable) } \\
\hline Liabilities & Balance Sheet & Permanent & $\sqrt{ }$ \\
\hline \multicolumn{4}{|c|}{$\begin{array}{l}\text { Liabilities (Unit: Thousands NTD): is defined as the future sacrifices of economic } \\
\text { benefits that the entity is obliged to make to other entities as a result of past } \\
\text { transactions or other past events, the settlement of which may result in the transfer or } \\
\text { use of assets, provision of services or other yielding of economic benefits in the future. }\end{array}$} \\
\hline Stockholder Equity & Balance Sheet & Permanent & $\sqrt{ }$ \\
\hline \multicolumn{4}{|c|}{$\begin{array}{l}\text { Stockholder Equity (Unit: Thousands NTD): is ownership of assets that may have } \\
\text { debts or other liabilities attached to them. Equity is measured for accounting purposes } \\
\text { by subtracting liabilities from the value of the assets. }\end{array}$} \\
\hline \multicolumn{4}{|c|}{ Output } \\
\hline Revenue & Income Statement & Temporary & $\mathrm{X}$ \\
\hline \multicolumn{4}{|c|}{$\begin{array}{l}\text { Revenues (Unit: Thousands NTD): is the total amount of income generated by the } \\
\text { sale of goods and services related to the primary operations of the business. }\end{array}$} \\
\hline Market Value & Income Statement & None & $\mathrm{x}$ \\
\hline \multicolumn{4}{|c|}{$\begin{array}{l}\text { Market value (Unit: Thousands NTD): refers to accounting for the "fair value" of an } \\
\text { asset or liability based on the current market price, or the price for similar assets and } \\
\text { liabilities, or based on another objectively assessed "fair" value. }\end{array}$} \\
\hline
\end{tabular}

In order to evaluate the $5 \mathrm{G}$ industry's relative efficiency, this study relied on a dynamic production process (as shown in Figure 1) to design a dynamic DEA model. The ensuing dynamic DEA process included 3 input variables, 2 carry-over (input variables) and 2 output variables. R\&D expenses, operating expenses, and the number of employees were considered input; liabilities and shareholders' equity were categorized as the "carry-over" of input; and operating income and market value were utilized as output (Homburg, 2001). Based on the aforementioned, the efficiency of the $t$ term was calculated via the dynamic DEA model. According to Cooper et al.'s (2001) rule of thumb for determining the number of decision-making units, "[t]he number of decision-making units should be at least three times the total 
number of input and output projects." A total of 360 decision-making units were used in this study. Since, as noted, 3 input items, 2 carryovers, and 2 output items were used in our model, the model constructed in this study can be said to have met construction validity.

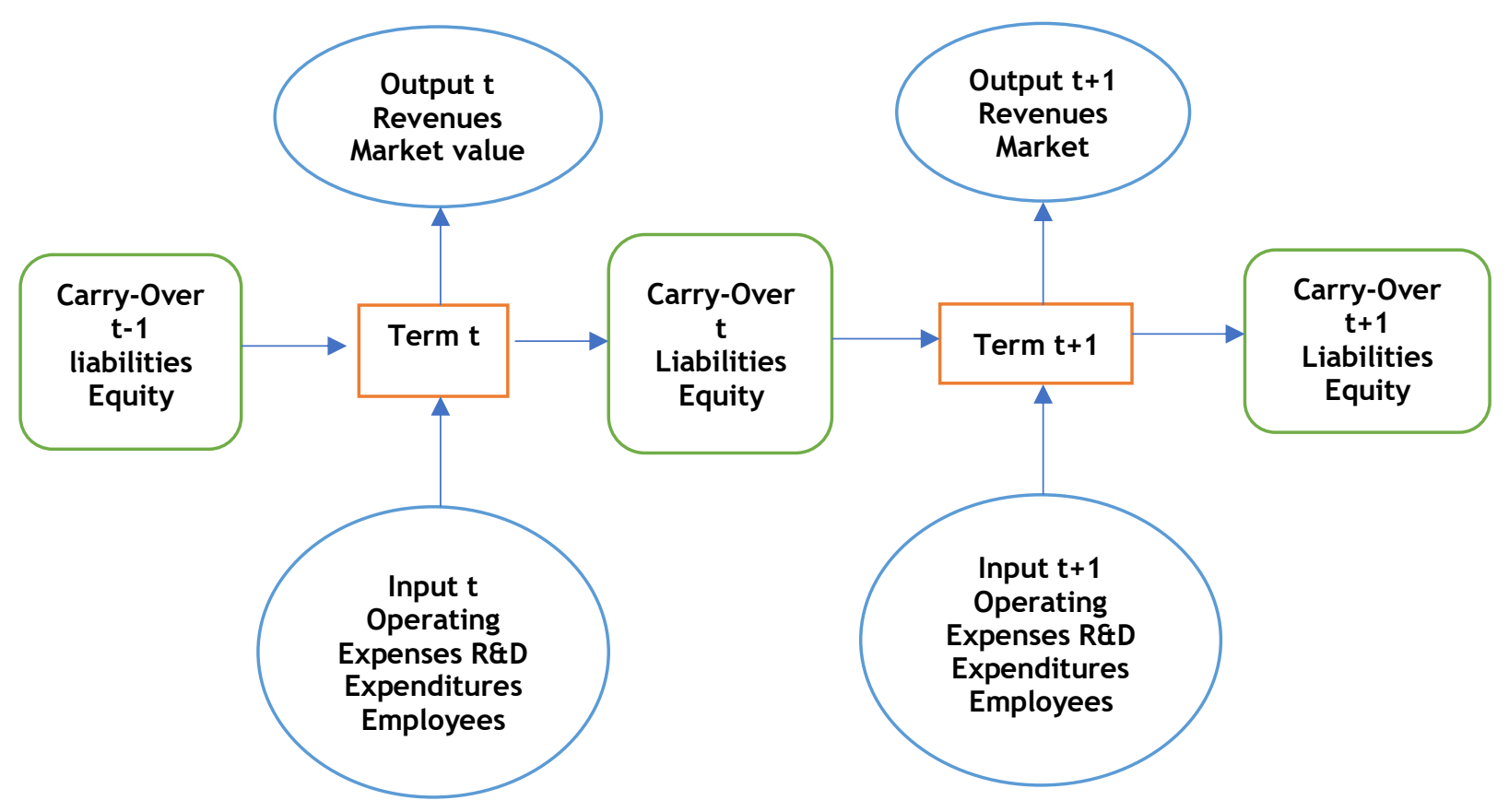

Figure 1: Dynamic production process

Table 2 Narrative statistics regarding the input and output of 5G-related industries in Taiwan from the first quarter of 2018 to the fourth quarter of 2020.From Table 2 it is evident that Taiwan's 5G-related industry R\&D expenses were the lowest in the first quarter, but highest in the fourth quarter, demonstrating positive results. Therefore, it is evident that multiplying growth allows industry development practitioners to provide a reference for its periodicity. 
Table 2: Sample's Descriptive Statistics

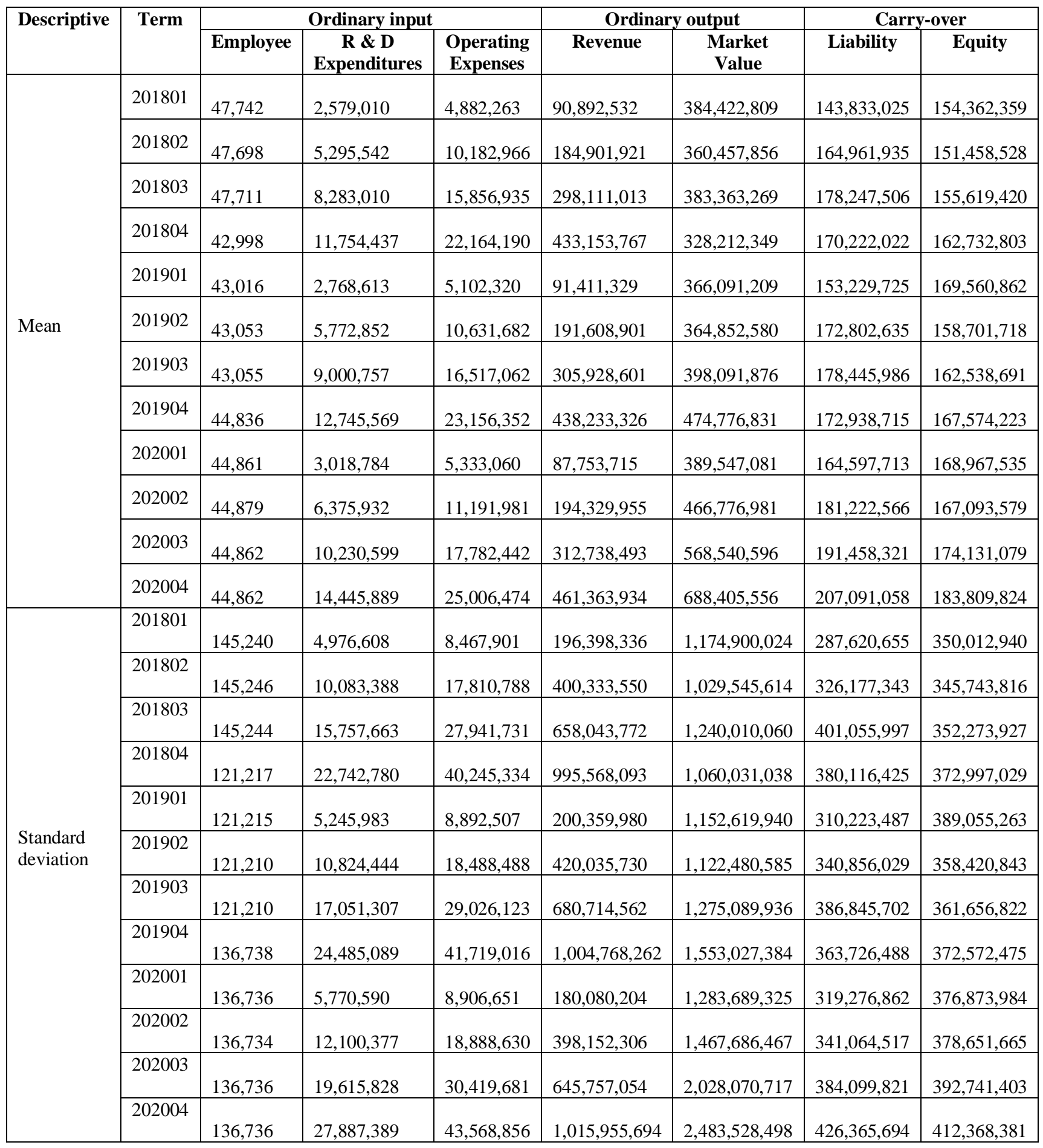




\subsection{Slack-based Measure in Dynamic DEA}

Several methods have been proposed to examine changes in the $5 \mathrm{G}$ industry over time via the measurement of its periodic performance. While these models can be said to consider the impact of time on performance, they tend to ignore the carryover activity between two consecutive time periods; another disadvantage is that they independently focus on different time periods in order to achieve partial optimization within a single time period (Fang, Lee, Hwang \& Chung, 2013). The proposed DSBM (Dynamic Slacks-Based 10 Measure) model developed by Tone and Tsutsui (2010) as compared with the radial model, can handle input, output and carry-over. Moreover, it addresses the carryover variable's dual-stage relative efficiency comparison problem due to the fact that it embodies the characteristic advantage of assuming that input or output variables can change non-proportionally. With the aforementioned limitations of previous models in mind, this study employed the DSBM (Dynamic Slacks-Based Measure) model with the aforementioned carry-over activity functionality to measure Taiwan's 5G industry's relative efficiency more accurately.

Consider the dynamic process shown in Figure 2, where this research is $n$ DMUs $(j=1, \ldots, n)$ over T terms $(t=1, \ldots, T)$. In each item, DMU has a common input $m$ input $(i=1, \ldots, m)$, carry-over $g$ link $(k=1, \ldots, g)$ and $r$ output $(p=1, \ldots, r)$. Let, $x_{i j}^{t}, z_{k j}^{t}$ and $y_{p j}^{t}$ denote the $j$ 's DMU input, link and output values at time $t$, respectively. The output-oriented DSBM model operates according to a variable return scale, and, thereby evaluates the efficiency of the observed company by solving the following score program, which can be converted to LP. For a detailed description of the model's process, please consult Tone (2001).

$$
\frac{1}{\tau_{0}}=\operatorname{Max} \frac{1}{T} \sum_{t=1}^{T}\left[1+\frac{1}{r+g}\left(\sum_{p=1}^{r} \frac{s_{p}^{t,+}}{y_{p o}^{t}}+\sum_{k=1}^{g} \frac{s_{k}^{t, c}}{z_{k o}^{t}}\right)\right]
$$

subject to

$$
\begin{array}{ll}
x_{i o}^{t}=\sum_{i=1}^{m} x_{i o}^{t} \lambda_{j}^{t}+s_{r t}^{t,-}, & (i=1, \ldots, m ; t=1, \ldots, T) \\
y_{p o}^{t}=\sum_{p=1}^{r} y_{r o}^{t} \lambda_{j}^{t}-s_{r t}^{t,+}, & (p=1, \ldots, r ; t=1, \ldots, T) \\
z_{k o}^{t}=\sum_{k=1}^{g} z_{k o}^{t} \lambda_{j}^{t}+s_{r t}^{t, c}, & (k=1, \ldots, g ; t=1, \ldots, T) \\
\sum_{j=1}^{n} z_{k j}^{t} \lambda_{j}^{t}=\sum_{j=1}^{n} z_{k j}^{t} \lambda_{j}^{t+1} & (\forall k ; t=1, \ldots, T-1) \\
\sum_{j=1}^{n} \lambda_{j}^{t}=1, & (t=1, \ldots, T) \\
\lambda_{j}^{t} \geq 0, s_{i}^{t,-} \geq 0, s_{p}^{t,+} \geq 0, s_{k}^{t, c} \geq 0
\end{array}
$$

where $\lambda_{j}^{t}, s_{i}^{t,-}, s_{p}^{t,+}$, and $s_{k}^{t, c}$ are intensity or slack variables denoting, respectively, input excess, output shortfall, and link excess. The constraint (3) is critical for the dynamic model, since it connects term $t$ and term $t+1$ activities. The constraint (4) assumes the variable returns-to-size for production. In other 
words, the production frontiers are spanned by the convex hull of the existing DMUs, and the production possibility set for the objective $\operatorname{DMU}_{O}(o=1, \ldots, n)$ is expressed by (2), (3), (4) and (5).

Let an optimal solution (1) subject to (2), (3), (4) and (5) be $\left\{\lambda_{j}^{t^{*}}, j=1,2, \ldots, n ; s_{i}^{t,-*}, i=1, \ldots, m ; s_{p}^{t,+*}, p=1, \ldots, r ; s_{k}^{t, c^{*}}, k=1, \ldots, g, t=1, \ldots, T\right\}$.

The output-oriented term efficiency for the objective $\mathrm{DMU}_{O}$ at time $t$ can be defined by

$\tau_{o t}^{*}=1 /\left[1+\frac{1}{r+g}\left(\sum_{p=1}^{r} \frac{s_{p}^{t,+^{*}}}{y_{p o}^{t}}+\sum_{k=1}^{g} \frac{s_{k}^{t, c^{*}}}{z_{k o}^{t}}\right)\right], \quad(t=1, \ldots, T)$.

The overall efficiency during the period $\left(\tau_{o}^{*}\right)$ is the average of the term efficiencies $\tau_{\text {ot }}^{*}$ as described below:

$\tau_{o}^{*}=\frac{1}{T} \sum_{t=1}^{T} \tau_{o t}^{*}$

\section{Empirical Analysis}

\subsection{Industry Efficiency Analysis}

In view of the $5 \mathrm{G}$ industry's rapid fluctuations, long-term planning and investment are necessary for a company to keep abreast of and adapt to constant change. The dynamic process model aims to evaluate these changes in the long-term relative efficiency of the $5 \mathrm{G}$ industry before and after their implementation into the industry. Figure 2 shows the average efficiency and corresponding standard deviation of the 5G industry from the first quarter of 2018 to the fourth quarter of 2020. The average efficiency is shown to be between 0.84 and 0.87 , and the trend is relatively stable with little change. These results indicate that the overall relative efficiency of R\&D investment in the $5 \mathrm{G}$ industry was relatively stable during this period; the relative efficiency standard deviation (St Dev) was between 0.22 and 0.26 , showing little change from the third quarter of 2019 to the second quarter of 2020. In other words, almost no difference was detected during this period. 


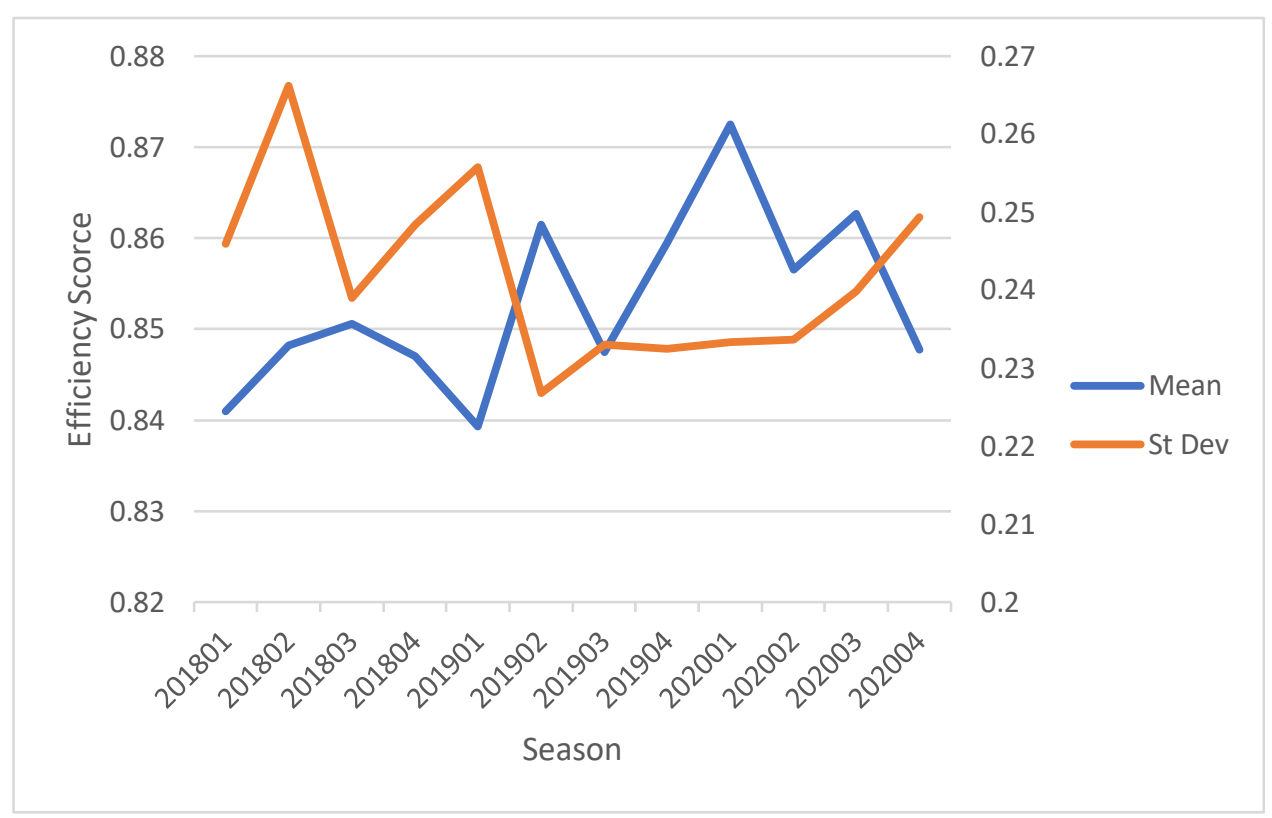

Figure 2: Comparison of the efficiency of the Mean and Standard Deviation

Table 3 shows 5G industry companies' relative efficiency values prior to and following the implementation of $5 \mathrm{G} R \& D$ investment in industry development. It is evident that the many companies' relative efficiency values reached a value of 1 . Simultaneously, the companies' relative efficiency values following the implementation of 5G R\&D investment in industry development were found to be lower than they were prior to the implementation of 5G R\&D investment in industry development. This was the case with the Win Semiconductors Corp., the Vanguard International Semiconductor Co., Sino-American Silicon Products, Inc., Zen Ding Technology Holding Limited, and the Chipbond Technology Corporation, as well as other five companies. However, when the relative efficiencies of 30 companies including Hon Hai Precision Industrial Corporation, Ltd., United Microelectronics Corp., Quanta Computer, Inc., the Realtek Semiconductor Corporation, the Unimicron Technology Corporation, the Inventec Corporation, and Chroma Ate, Inc. - were compared with one other prior to and following 5G R\&D industrial development investment, the relative efficiency of seven companies had improved. In order to gain an understanding of whether or not significant performance differences existed between the different periods, this study employed Friedman's (1937) two-way analysis of variance (Two-Way ANOVA). With the significance level under 5\%, this article shows that there was, indeed, a significant difference in the relative efficiency of the $5 \mathrm{G} \mathrm{R} \& \mathrm{D}$ investment industry during this period. 
Table 3: 5G Industry Relative Efficiency Values

\begin{tabular}{|c|c|c|c|}
\hline \multirow[b]{2}{*}{ Company } & \multicolumn{3}{|c|}{ Industry Relative Efficiency Value Mean } \\
\hline & $\begin{array}{l}\text { Overall } \\
\text { Score }\end{array}$ & $\begin{array}{c}\text { Before R\&D } \\
\text { Expenditures Input }\end{array}$ & $\begin{array}{c}\text { After R \& D } \\
\text { Expenditures Input }\end{array}$ \\
\hline Taiwan Semiconductor Manufacturing Co., & 1.000 & 1.000 & 1.000 \\
\hline Hon Hai Precision Ind. Co., Ltd. & 0.577 & 0.553 & 0.831 \\
\hline Mediatek Inc. & 1.000 & 1.000 & 1.000 \\
\hline United Microelectronics Corp. & 0.301 & 0.284 & 0.460 \\
\hline Largan Precision Co., Ltd. & 1.000 & 1.000 & 1.000 \\
\hline Quanta Computer Inc. & 0.984 & 0.983 & 1.000 \\
\hline Taiwan Mobile Co., Ltd. & 1.000 & 1.000 & 1.000 \\
\hline Silergy Corp. & 1.000 & 1.000 & 1.000 \\
\hline Realtek Semiconductor Corporation & 0.630 & 0.619 & 0.814 \\
\hline Novatek Microelectronics Corp. & 1.000 & 1.000 & 1.0000 \\
\hline Accton Technology Corp. & 1.000 & 1.000 & 1.000 \\
\hline Pegatron Corporation & 1.000 & 1.000 & 1.000 \\
\hline Far EasTone Telecommunications Co., Ltd. & 1.000 & 1.000 & 1.000 \\
\hline Win Semiconductors Corp. & 0.562 & 0.659 & 0.343 \\
\hline Unimicron Technology Corp. & 0.311 & 0.316 & 0.417 \\
\hline Vanguard International Semiconductor Co. & 0.950 & 0.960 & 0.930 \\
\hline Sino-American Silicon Products Inc. & 0.747 & 0.798 & 0.643 \\
\hline Compal Electronics, Inc. & 1.000 & 1.000 & 1.000 \\
\hline Wistron Corporation & 1.000 & 1.000 & 1.000 \\
\hline Walsin Technology Corporation & 1.000 & 1.000 & 1.000 \\
\hline Inventec Corporation & 0.909 & 0.903 & 0.999 \\
\hline Powertech Technology Inc. & 0.923 & 0.923 & 1.000 \\
\hline Chroma Ate Inc. & 0.457 & 0.459 & 0.480 \\
\hline Zhen Ding Technology Holding Limited & 0.371 & 0.399 & 0.313 \\
\hline WPG Holdings Limited & 1.000 & 1.000 & 1.000 \\
\hline Tripod Technology Corporation & 1.000 & 1.000 & 1.000 \\
\hline Compeq Manufacturing Co., Ltd. & 1.000 & 1.000 & 1.000 \\
\hline Elite Material Co., Ltd. & 1.000 & 1.000 & 1.000 \\
\hline Chipbond Technology Corporation & 0.608 & 0.716 & 0.420 \\
\hline Genius Electronic Optical Co., Ltd. & 1.000 & 1.000 & 1.000 \\
\hline
\end{tabular}

Note. Before R\&D Expenditures as Inputs:201801-202002, After R\&D Expenditures as Inputs:202003-202004. 
In general, Table 4 demonstrates that from the first quarter of 2018 to the fourth quarter of 2020, the implementation of 5G R\&D investment in industrial development did, indeed, improve the relative efficiency of some enterprises; moreover, following the implementation of industrial development, the 5G industry-related companies' average overall dynamic relative efficiency was slightly higher than it was prior to the implementation of 5G R\&D investment. However, there was no significant difference, suggesting that 5G R\&D investment is, indeed, necessary.

\subsection{Can we characterize 5GCs according to R\&D expenditures?}

Overall, it was discovered that $5 \mathrm{G}$ R\&D expenditure plays a vital role in a company's ability to face drastic environmental fluctuations, maintain its competitive marketplace standing, and sink or swim amidst cut-throat competition. In the end, a company's management team is the ultimate decision maker in deciding whether or not to invest in $5 \mathrm{G} R \& \mathrm{D}$ activities.

According to the Taiwan Industry Map (2021), Taiwan's 5G industry is composed of independent production systems, namely, key chips, design, manufacturing and assembly, brand terminals, and downstream category and other manufacturers. In order to explore further the relationship between the relative efficiency of 5Grelated companies in the industry category and 5G companies' R\&D investment, this survey divides 5G-related companies into four major categories:

1) Key-chips.

2) Design, manufacturing and assembly.

3) Brand terminals.

4) Downstream, and assesses their relative operating efficiency for each year (as shown in Table 4 and Figure 3).

In terms of relative efficiency values, from the first quarter of 2018 to the third quarter of 2019, at a statistical level of 5\%, a statistically significant different relationship was found. However, there was no statistically significant difference between the fourth quarter of 2019 and the fourth quarter of 2020 at the 5\% statistical level. Moreover, the relative efficiency values of the four major categories of key chips, design, manufacturing and assembly, brand terminals, and downstream appeared to be approaching 0.8. This demonstrates that key-chipcategory companies' relative efficiency values did, indeed, increase quarter by quarter, the relative efficiency values of brand terminals and downstream companies fell quarter by quarter, while the relative efficiency values of design, manufacturing and assembly companies remained stable. 
Table 4: 5G Companies' Characteristics and Relative Efficiency Values

\begin{tabular}{|c|c|c|c|c|c|}
\hline & & Key chip & $\begin{array}{c}\text { Design, } \\
\text { manufacture } \\
\text { and assembly }\end{array}$ & $\begin{array}{c}\text { Brand } \\
\text { terminal }\end{array}$ & Downstream \\
\hline Term & No. & 4 & 19 & 4 & 3 \\
\hline & Mean & 0.582 & 0.853 & 0.987 & 0.914 \\
\hline 201801 & $\mathrm{P}$-value & $0.001^{*}$ & & & \\
\hline & Mean & 0.577 & 0.871 & 0.994 & 0.874 \\
\hline 201802 & $\mathrm{P}$-value & $0.001^{*}$ & & & \\
\hline & Mean & 0.539 & 0.886 & 0.973 & 0.879 \\
\hline 201803 & P-value & $0.001^{*}$ & & & \\
\hline 201804 & Mean & 0.564 & 0.875 & 0.958 & 0.901 \\
\hline 201804 & P-value & $0.007^{*}$ & & & \\
\hline & Mean & 0.591 & 0.865 & 0.935 & 0.880 \\
\hline 201901 & $\mathrm{P}$-value & $0.005^{*}$ & & & \\
\hline רח010 & Mean & 0.648 & 0.894 & 0.900 & 0.892 \\
\hline 201902 & P-value & $0.035^{*}$ & & & \\
\hline & Mean & 0.639 & 0.878 & 0.900 & 0.864 \\
\hline 201903 & $\mathrm{P}$-value & $0.046^{*}$ & & & \\
\hline 201004 & Mean & 0.622 & 0.900 & 0.907 & 0.854 \\
\hline 201904 & P-value & 0.082 & & & \\
\hline 20ว001 & Mean & 0.648 & 0.904 & 0.872 & 0.970 \\
\hline 202001 & P-value & 0.100 & & & \\
\hline רחתברבי & Mean & 0.688 & 0.894 & 0.864 & 0.836 \\
\hline$\angle 0 \angle 00 \angle$ & P-value & 0.092 & & & \\
\hline 202003 & Mean & 0.795 & 0.889 & 0.866 & 0.784 \\
\hline $20<003$ & P-value & 0.075 & & & \\
\hline מחתר & Mean & 0.759 & 0.878 & 0.844 & 0.779 \\
\hline 202004 & $\mathrm{P}$-value & 0.109 & & & \\
\hline מרחתר & Mean & 0.759 & 0.878 & 0.844 & 0.779 \\
\hline 202004 & P-value & 0.109 & & & \\
\hline
\end{tabular}

Note: ${ }^{*} p<0.05$ 


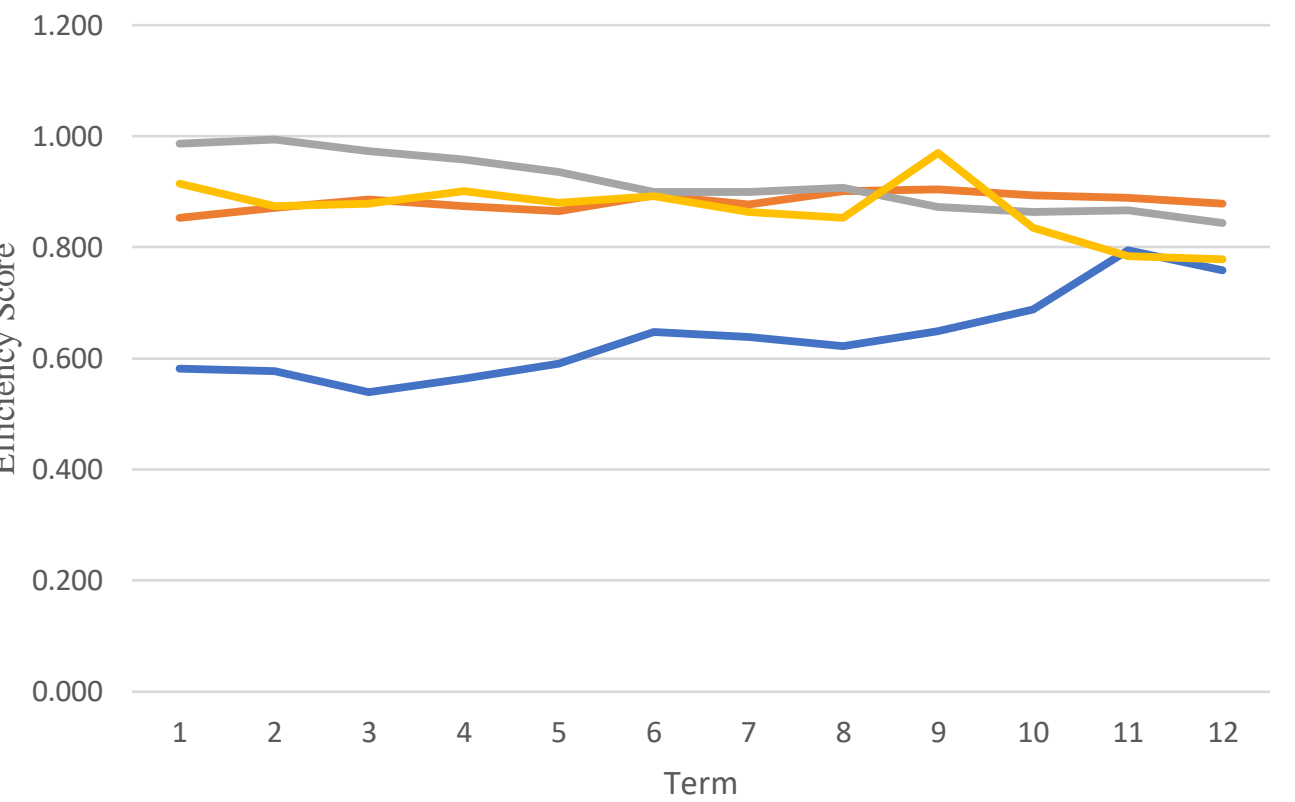

$\longrightarrow$ Key chip $\longrightarrow$ Design, manufacture and assembly $\longrightarrow$ Brand terminal $\longrightarrow$ Downstream

Figure 3: Efficiency values for each category from 2018 to 2020

In view of the $5 \mathrm{G}$ industry's rapid changes, long-term planning and $\mathrm{R} \& \mathrm{D}$ investment appear to be crucial determiners of a company's survival. The dynamic production process described herein aimed to evaluate the relative efficiency of the industry's long-term operations brought about by $5 \mathrm{G} R \& D$ investment. From the first quarter of 2018 to the fourth quarter of 2020, the relative efficiency performance value of brand-terminal companies was found to be the highest at 0.917 ; the value of the design, manufacturing and assembly companies was 0.882 , the downstream companies' relative efficiency value of 0.869 , while the key-chip companies' value was only 0.638 . At the $5 \%$ statistical level, a statistically significant different relationship was detected between industries and business performance (as shown in Table 4 and Figure 3). This can most likely be explained by the fact that the profits of the IC design, manufacturing and assembly industry have been recently pushed to new heights by Taiwan Semiconductor Manufacturing Co. (TSMC) and other superstar-firms in the industry. As for key chips, their performance probably derives from the fact that two chip manufacturing companies, Mediatek, Inc. and Realtek Semiconductor Corporation, were successful at maintaining positive profits.

The analysis of the operating performance of 30 5G-industry companies from the first quarter of 2018 to the fourth quarter of 2020 is depicted in Table 5.

Table 5 shows the average dynamic relative efficiency of each overall sample and makes a distinction between a company's performance in industry development 
prior to the implementation of $5 \mathrm{G} \mathrm{R} \& \mathrm{D}$ investment and its performance following the implementation of industry development from the overall sample. In order to ascertain whether not there was a statistically significant difference in relative efficiency before and after the implementation of industrial development, the Nonparametric Methods Kruskal-Wallis Test was used to measure the score of the non-parametric distribution function.

As shown in Table 5, the average 5G industry development efficiency score before the implementation of R\&D investment was 0.827 , which is slightly higher than the average efficiency score of 0.824 following the implementation of industrial development; however, as far as key chip, design, manufacturing and assembly, brand terminals, downstream and other industry categories are concerned there was a significant difference in company performance prior to the implementation of industrial development, but there was no significant difference after the implementation of industrial development.

The performance scores of companies in the key chip industry category increased before and after the implementation of the industry development, companies in the design, manufacturing and assembly industries category remained stable, and the performance of industry-related companies, such as brand terminal downstream, declined.

In sum, the R\&D capabilities of the $5 \mathrm{G}$ industry key wafer companies examined in this sample were successful as obtaining the funds required for $R \& D$ investment due to the abundance of resource advantages, such as talent, capital, technology and management capabilities. These, subsequently, increased a company's overall performance by improving key technologies and implementing them in to the company's internal network.

Table 5: Relative Efficiency between pre and post R\&D Expenditures as Inputs

\begin{tabular}{|c|c|c|c|c|c|c|}
\hline & Overall & Key chip & $\begin{array}{c}\text { Design, } \\
\text { manufacture } \\
\text { and assembly }\end{array}$ & $\begin{array}{l}\text { Brand } \\
\text { terminal }\end{array}$ & Downstream \\
\hline & & 30 & 4 & 19 & 4 & 3 \\
\hline \multirow{2}{*}{$\begin{array}{c}\text { Pre R\&D } \\
\text { Expenditures Input }\end{array}$} & Mean & 0.827 & 0.610 & 0.881 & 0.929 & 0.882 \\
\hline & P-value & $0.000^{*}$ & & & & \\
\hline \multirow{2}{*}{$\begin{array}{c}\text { Post R\&D } \\
\text { Expenditures Input }\end{array}$} & Mean & 0.824 & 0.777 & 0.883 & 0.855 & 0.781 \\
\hline & P-value & $0.240^{*}$ & & & & \\
\hline \multirow{2}{*}{ Overall score } & Mean & 0.826 & 0.638 & 0.882 & 0.917 & 0.869 \\
\hline & P-value & $0.000^{*}$ & & & & \\
\hline
\end{tabular}

Note: $* \mathrm{p}<0.05$

The results of Table 4 and Table 5 support the notion that 5G-industry companies' overall dynamic efficiency is related to its company category model before and after the implementation of industrial development. The estimated p-value range of the $\mathrm{K}-\mathrm{W}$ test was less than 0.05 overall, indicating that the null hypothesis of equal 
distribution cannot be rejected. Industry development was shown to be less than 0.05 prior to the implementation, indicating that the scale of $R \& D$ and enterprise types are significantly positively correlated. The average efficiency of companies with high levels of R\&D in the post-industrial development period was higher than that of companies with low investment, and the difference was very significant. The results, therefore, confirm that downstream companies are farther from the effective frontier and have lower R\&D scale efficiency than key chip companies. However, the results of dynamic allocation efficiency, as shown in Tables 4 and 5 show that when selecting input and output combinations that minimize the inefficiency of R\&D capabilities, 5G downstream companies encounter more problems with relatively low efficiency.

\section{Conclusion}

This article offers three key contributions to our current understanding of the relative efficiency of the $5 \mathrm{G}$ industry. First, it addresses a lacuna in the literature by focusing on the dynamic relative efficiency of companies in the 5G industry, an industry occupying a pivotal position in the international economy. Second, it reveals the importance of the DEA dynamic analysis' ability to calculate the carryover function when assessing a company's potential industrial development competency. Lastly, it shedding light on how to analyze upper and lower related variables.

With regards to this study's incidental contribution to 5G-related industries, it provides empirical evident proving that $5 \mathrm{G} R \& D$ investment industry companies are usually relatively efficient following the implementation of industrial development, because industrial development is affected positively by $R \& D$. In other words, investment was found to be a bellwether of success and survival in the $5 \mathrm{G}$ industry, and a company's market value was shown to be positively correlated with its subsequent R\&D capabilities. Moreover, the $5 \mathrm{G}$ industry displays positive economies of scale in terms of operating expenses, and R\&D investment capabilities have an important impact on performance (Chou et al., 2012). Compared with the 15 constituents of the Taiwan 50 Index and the non-Taiwan 50 Index constituents, the overall operating efficiency of the Taiwan 50 Index constituent stocks was found to be higher.

As far as the entire sample is concerned, the present analysis demonstrates that there is, indeed, a significant difference in the relationship between study scale and efficiency. As more research funds support future projects, the $5 \mathrm{G}$ industry will undoubtedly contribute to yet further growth. More research is necessary that evaluates more succinctly the role of carry-over variables in distinguishing and predicting technological development. One such possibility for future studies would be to combine data-mining techniques with a larger number of context variables to identify the most relevant techniques. 


\section{References}

[1] Chen, P.Y. and Chiang, H.C. (2018). The efficiency analysis of Taiwan's artificial intelligence industry. Management Information Computing, 7(2), 332-341.

[2] Chou, Y.C., Shao, B.B., and Lin, W.T. (2012). Performance evaluation of production of IT capital goods across OECD countries: A stochastic frontier approach to Malmquist Index. Decision Support Systems, 54(1), 173-184.

[3] Cooper, W.W., Li, S., Seiford, L.M., Tone, K., Thrall, R.M. and Zhu, J. (2001). Sensitivity and Stability Analysis in DEA: Some Recent Developments. Journal of Productivity Analysis, 15, (3) , 217-246.

[4] Debnath, R.M., and Shankar, R. (2008). Benchmarking telecommunication service in India: An application of data envelopment analysis. Benchmarking: An International Journal.

[5] Diaz-Balteiro, L., Herruzo, A.C., Martinez, M., and Gonzalez-Pachon, J. (2006). An analysis of productive efficiency and innovation activity using DEA: An application to Spain's wood-based industry. Forest Policy and Economics, 8(6), 762-773.

[6] Eberhart, A., Maxwell, W., and Siddique, A. (2008). A reexamination of the tradeoff between the future benefit and riskiness of R\&D increases. Journal of Accounting Research, 46(1), 27-52.

[7] Fang, H.H., Lee, H.S., Hwang, S.N., and Chung, C.C. (2013). A slacks-based measure of super-efficiency in data envelopment analysis: An alternative approach. Omega, 41(4), 731-734.

[8] Friedman, M. (1937). The use of ranks to avoid the assumption of normality implicit in the analysis of variance. Journal of the American statistical association, 32(200), 675-701.

[9] Gerpott, T.J., and Ahmadi, N. (2015). Advancement of indices assessing a nation's telecommunications development status: A PLS structural equation analysis of over 100 countries. Telecommunications Policy, 39(2), 93-111.

[10] Golany, B., and Roll, Y. (1989). An application procedure for DEA. Omega, $17(3), 237-250$.

[11] Harb, G. (2017). The economic impact of the Internet penetration rate and telecom investments in Arab and Middle Eastern countries. Economic Analysis and Policy, 56, 148-162.

[12] Hashimoto, A., and Haneda, S. (2008). Measuring the change in R\&D efficiency of the Japanese pharmaceutical industry. Research Policy, 37, 18291836.

[13] Homburg, C. (2001). Using data envelopment analysis to benchmark activities. International Journal of Production Economics, 73(1), 51-58.

[14] Industrial Economic Research Center. (2021). Taiwan Industry Map.

[15] Jia, W. (2016). Enlightenment from the innovative application of 4G communication technology in the mobile library. Paper presented at the 2016 International Conference on Smart City and Systems Engineering (ICSCSE). 
[16] Kotabe, M., and Zhao, H. (2002). A Taxonomy of sourcing strategic types for MNCs operating in China. Asia Pacific Journal of Management, 19(1), 11-27.

[17] Kumar, A., Shankar, R., and Debnath, R.M. (2015). Analyzing customer preference and measuring relative efficiency in telecom sector: A hybrid fuzzy AHP/DEA study. Telematics and Informatics, 32(3), 447-462.

[18] Lu, C.C., Kao, L.J. and Fu, H.P. (2016). Applying Independent Component Analysis and DEA to measure efficiencies of the medium-size semiconductor packaging and testing companies in Taiwan. Sun Yat-sen Management Review, 24(3), 503-530.

[19] Lu, W.M., and Hung, S.W. (2011). Exploring the operating efficiency of technology development programs by an intellectual capital perspective - A case study of Taiwan. Technovation, 31(8), 374-383.

[20] Pandit, S., Wasley, C.E., and Zach, T. (2011). The effect of research and development $(R \& D)$ inputs and outputs on the relation between the uncertainty of future operating performance and R\&D expenditures. Journal of Accounting, Auditing \& Finance, 26(1), 121-144.

[21] Seiford, L.M., and Zhu J. (1999). Profitability and marketability of the top 55 U.S. commercial banks. Management Science, 45(9), 1270-1288.

[22] Tone, K. (2001). A slacks-based measure of efficiency in data envelopment analysis. European Journal of Operational Research, 130(3), 498-509.

[23] Tone, K., and Tsutsui, M. (2010). Dynamic DEA: A slacks-based measure approach. Omega, 38(3), 145-156.

[24] Yang, H.H., and Chang, C.Y. (2009). Using DEA window analysis to measure efficiencies of Taiwan's integrated telecommunication firms. Telecommunications Policy, 33(1-2), 98-108. 